\title{
Prevalence and Outcome of Operative Vaginal Delivery among Mothers Who Gave Birth at Jimma University Medical Center, Southwest Ethiopia
}

\author{
Zenebe Hubena, ${ }^{1}$ Ahadu Workneh, ${ }^{2}$ and Yibeltal Siraneh $\mathbb{D D}^{3}$ \\ ${ }^{1}$ Kuyu General Hospital, North Showa, Oromia Regional State, Ethiopia \\ ${ }^{2}$ Department of Obstetrics and Gynecology, Faculty of Medical Sciences, Institute of Health, Jimma University, Ethiopia \\ ${ }^{3}$ Department of Health Economics, Management and Policy, Faculty of Public Health, Institute of Health, Jimma University, Ethiopia
}

Correspondence should be addressed to Yibeltal Siraneh; yibeltal_siraneh@yahoo.com

Received 22 January 2018; Revised 4 June 2018; Accepted 14 June 2018; Published 9 July 2018

Academic Editor: Marco Scioscia

Copyright (C) 2018 Zenebe Hubena et al. This is an open access article distributed under the Creative Commons Attribution License, which permits unrestricted use, distribution, and reproduction in any medium, provided the original work is properly cited.

\begin{abstract}
Background. Operative vaginal deliveries (OVD) are vaginal deliveries accomplished with the use of a vacuum device or forceps. If it is technically feasible and can be safely accomplished, termination of second stage labor by operative vaginal delivery is indicated in any condition threatening the mother or fetus that is likely to be relieved by delivery. Hence, the objective of this study is to assess the prevalence, common indication, outcome, and associated factors of operative vaginal delivery among mothers who gave birth in Jimma University Medical Center (JUMC). Method. A facility-based cross-sectional study design was used in maternity ward on 242 mothers who gave birth by operative vaginal delivery from December 01, 2016, to May 30, 2017. The clinical data were collected using a check list, recordings of intrapartum fetal and maternal state, and immediate fetomaternal outcomes. The study participants were recruited using consecutive sampling method. Sociodemographics and related data were collected at exit using structured interviewer administered questionnaire which was developed by reviewing different literature and the remaining information abstracted from patient charts. Data were entered to Epidata 3.1 and exported to SPSS version 21 for analysis. Bivariate analysis was done to identify candidate variables using $\mathrm{p}<0.25$. Multivariable logistic regression was used to control the effect of confounding variables and to identify factors affecting the fetomaternal outcome. Statistical significance was declared at $\mathrm{P}<0.05$ using adjusted OR with $95 \%$ CI. Result. Out of the 2348 pregnant mothers who gave birth in the labor ward of JUMC during the 6 months of the study period, $242(10.3 \%)$ were by operative vaginal delivery (OVD). The commonest indication for operative vaginal delivery is found to be nonreassuring fetal heart rate pattern, $136(56.2 \%)$. Out of all neonates delivered by operative vaginal delivery 210 (86.8\%) had favorable outcome. Of all mothers who gave birth by operative vaginal delivery $232(95.9 \%)$ had favorable outcome. Type of instrument used for operative vaginal delivery (AOR=0.228, 95\%CI: $0.078,0.671$ ) and presence of grade two $(\mathrm{AOR}=0.163,95 \% \mathrm{CI}: 0.031,0.858)$ and grade three $(\mathrm{AOR}=0.088,95 \% \mathrm{CI}: 0.024,0.327)$ meconium stained amniotic fluid are factors affecting neonatal outcome while neonatal birth weight ( $\mathrm{AOR}=0.007,95 \% \mathrm{CI}$ : $0.000,0.151)$ is factor affecting maternal outcome of operative vaginal delivery. Conclusion. Prevalence of operative vaginal delivery is found to be $10.3 \%$ with the commonest indication of nonreassuring fetal heart rate pattern. Nearly all of mothers and neonates had favorable outcome. Type of instrument applied for operative vaginal delivery is the strongest predictor of neonatal outcome while neonatal birth weight is the only predictor of maternal outcome identified in this study.
\end{abstract}

\section{Background}

Operative vaginal deliveries are vaginal deliveries accomplished with the use of a vacuum device or forceps. If it is technically feasible, it can be safely accomplished. Termination of second stage of labor by operative vaginal delivery is indicated in any condition threatening the mother or fetus.
According to the birth certificate data from the National Vital Statistics Report, forceps or vacuum-assisted vaginal delivery was used for 3.6\% of births in the United States in 2010, and it accounts for around $11 \%$ and $17.3 \%$ of births in Royal College of obstetricians and gynecologists, Australia, and in Tikur Anbessa Specialized hospital, Ethiopia, respectively [1-4]. 
When prerequisites have been met, the appropriate indications for consideration of either forceps delivery or vacuum extraction are prolonged second stage, nonreassuring fetal heart rate tracing, or shortening of the second stage of labor for maternal benefit. Both forceps and vacuum have the potential to cause fetal and neonatal injury; however, the incidence of maternal injury is less with the vacuum than with forceps. In order to minimize both maternal and fetal risks, the operator must be familiar with the indications, contraindications, application, and use of the particular instrument. It is recommended that OVD should be performed from either a low or outlet station [5]. Studies revealed that prevalence of OVD ranged from 3 to $11 \%$ in different settings $[2,6]$.

Vacuum extractor is less likely to achieve a successful vaginal delivery and to cause serious maternal injury than applying the forceps. Although the vacuum is associated with a greater incidence of cephalohematoma, other facial/cranial injuries are more common with forceps [7].

Although operative vaginal delivery may be performed, as infrequently as in $1.5 \%$ of deliveries in some countries, it may be as high as $15 \%$ in other countries. In the United Kingdom, the rates of instrumental vaginal delivery range between $10 \%$ and $15 \%$; these rates have remained fairly constant, although there has been a change in preference of instrument [6].

But currently studies show that there is a decreasing trend of instrumental deliveries and is a major concern in health care system all over the world. Assessing the trends of instrumental deliveries and its major indications would be useful in adopting suitable measures to reduce the caesarean section rate and the problems associated with it. A five-year retrospective study conducted on trends of instrumental deliveries at a tertiary teaching hospital in Puducherry, India, showed among a total of 5445 deliveries that occurred during study period, $7.7 \%$ were instrumental vaginal deliveries. The yearwise rate of instrumental deliveries ranges from $6.1 \%$ to $9.8 \%$. During the study period (except during year 2011), a declining trend for instrumental deliveries was observed [8].

Studies revealed that the most common indication for OVD is to shorten second stage of labor considering maternal condition and the commonest unfavorable outcomes of OVD varies. Study done in Shankar Nagar and Raipur, India, reported that the most common indication was to cut short second stage of labor (52.5\%) (preeclampsia, heart disease) followed by prolonged second stage of labor (22.5\%), fetal distress, and maternal exhaustion. The risk of neonatal morbidity was similar between infants delivered by vacuum or forceps [9]. The commonest maternal complication was postpartum hemorrhage and genital tract laceration [10]. Evidence evaluating neonatal morbidity after instrumental vaginal delivery is inconsistent. A systematic review of 10 trials comparing vacuum extraction with forceps delivery found no significant differences in APGAR scores at one and five minutes and few serious injuries in neonates, although the vacuum extractor was associated with an increase in cephalhematoma and retinal hemorrhage [11]. In JUMC, no study conducted to assess the prevalence, indications, fetomaternal outcome, and associated factors of operative vaginal delivery.

\section{Methods and Participants}

2.1. Study Area and Period. The study was conducted in Jimma University Medical Center (JUMC) which is located $352 \mathrm{kms}$ Southwest of Addis Ababa. JUMC is found in Jimma zone of Oromia regional state within Jimma Town. It is one of the oldest specialized teaching hospitals (currently renamed as medical center) in the country giving services to people living in Jimma zone and serve as a referral hospital in the Southwest Ethiopia. It is teaching center for many clinical undergraduate and postgraduate specialty students. Department of Obstetrics and Gynecology has two inpatient (gynecology and obstetrics), one maternal health clinic, one gynecologic OPD, one family planning clinic, and referral clinics (gynecology oncology, benign gynecologic diseases, and high risk pregnancy). It has eight obstetricians and gynecologists and 32 residents from year I to III. The labor ward has 7 beds in first stage and 4 delivery couches. Maternity ward has 50 beds, 2 emergency operation rooms, and one recovery room with 2 beds and 2 resuscitation tables for newborns. There were a total of 2,654 deliveries recorded over eight months from November 1, 2015, to June 30, 2016, of which 266 were by OVD.

2.2. Study Design and Population. A facility-based crosssectional study design was used. All mothers who gave birth at JUMC during the study period were the source population. All mothers who gave birth by operative vaginal delivery were included. All mothers for whom OVD indicated and fulfilled prerequisites (fetal head being engaged, vertex presentation, cervix being fully dilated ( $8 \mathrm{~cm}$ for ventouse), membranes ruptured, exact position of head known, fetal size estimated (weight and ga), informed consent, maternal bladder being empty, adequate maternal pelvis, and back-up plan in place in case of failure to deliver) were eligible. Mothers for whom OVD was indicated but with IUFD and fetus with congenital anomaly were not eligible.

2.3. Sample Size Determination. The sample size was determined using a single population proportion formula $n=z^{2} p$ $(1-\mathrm{p}) / \mathrm{d},{ }^{2}$ where $\mathrm{p}(17.3 \%)$ is the estimate of the proportion of operative vaginal delivery elsewhere. Considering all recommended values for each parameter, the sample was estimated to be 220 . By adding $10 \%$ of this sample size for expected nonresponse rate, the final sample size becomes 242. Prevalence of OVD was taken $17.3 \%$ as obtained from a retrospective study conducted in 2004 at Tikur Anbessa Specialized Hospital, Addis Ababa, Ethiopia. All mothers who gave birth by OVD during study period were included using consecutive sampling technique till the required sample size completed.

Study variables were fetal parameters (FHR, GA, neonatal birth weight), obstetric related variables (cervical dilatation, uterine contraction/maternal effort, descent/station, need for rotation, indication for OVD, type of instrument used for OVD, timing of application of OVD (on arrival/followed), status of liquor), maternal parameters (age, parity, residency, ANC follow-up), fetomaternal outcomes (serious maternal 
morbidity or death, postpartum hemorrhage, blood transfusions, episiotomy extension, third and fourth degree tears, cervical laceration, need for major surgery (hysterectomy, urinary retention and bladder dysfunction, low APGAR score, admission to NICU, need for resuscitation at delivery, neonatal sepsis at neonatology, birth trauma (fractured bone, cephalhematoma), and condition at discharge (normal, improved, died).

2.4. Data Collection Tools and Procedures. The tool was developed by reviewing different literature and translated into local languages (Afan Oromo, Amharic) and then back translated to English by third party to check its consistency. Structured interviewer administered questionnaire used to interview mothers at exit. Two obstetrics and gynecology residents and 3 midwives were trained on how to interview eligible mothers and abstract information from respective charts. Checklist was used to extract data from the patient chart. The first part required information about patient's age, gravidity, parity and estimated gestation age. Second part required the parameters of labor which were fetal heart rate, liquor state, cervical dilatation, descent of head, uterine contraction, and maternal BP. The third part required the fetal outcomes which were assessed in terms of live birth (APGAR score at first and fifth minutes), need of resuscitation, admission to neonatal ward for special care, and the reasons for admission. The fourth part included information about the mode of delivery (OVD) and immediate maternal outcomes. Immediate maternal outcomes were recorded as favorable and unfavorable if the woman got $\mathrm{PPH}$, perineal tear (third degree and above), need of blood transfusion, urinary bladder injury, hysterectomy, or bowel injury.

\subsection{Operational Definitions}

2.5.1. Operative Vaginal Deliveries (OVD). Vaginal deliveries are accomplished with the use of a vacuum device or forceps.

2.5.2. Indication of $O V D$. It means any condition threatening the mother or fetus that is likely to be relieved by immediate delivery when prerequisites are fulfilled.

2.5.3. Asphyxia. Asphyxia is a condition in which viable newborn fails to attain or initiate respirations after delivery.

2.5.4. APGAR Score. APGAR score is method of assessing fetal conditions at time of delivery.

2.5.5. Low APGAR Score. APGAR score of less than seven is considered low.

2.5.6. Birth Trauma. Birth trauma is any trauma to the newborn as a result of labor and delivery like cephalohematoma, subgaleal hemorrhage, retinal hemorrhage, shoulder dystocia, clavicular fracture, and scalp lacerations.
2.5.7. Favorable Outcome. If mother and neonate has no complications, this is considered a favorable outcome.

2.5.8. Unfavorable Outcome. The unfavorable outcome is when mother and neonate developed complications (maternal complications like PPH, genital tear, need of blood transfusion, need of major surgery, death, and neonatal complications like low APGAR score, need of resuscitation, admission to NICU, and neonatal death).

2.5.9. Episiotomy Extension. Episiotomy extension is an incision that is deeper or longer than is necessary to permit the birth of newborn.

2.6. Data Processing and Analysis. The collected data were cleaned, entered in to Epi-data 3.1, and exported to SPSS for windows version 21 for data analysis. Descriptive statistics used to describe the main features of the data. Bivariate analysis was done to identify candidate variable using $\mathrm{p}<0.25$. Multivariate Logistic regression was used to control the effect of confounding variables. Variables having $\mathrm{P}<0.25$ from bivariate analysis were included in multivariable logistic regression analysis. Finally, statistical significance declared at $\mathrm{P}<0.05$ using adjusted OR with 95\% CI.

2.7. Ethical Considerations. Ethical clearance was taken from Institutional Review Board (IRB) of Jimma University Institute of health, and permission letter was obtained from JUMC including Obstetrics and Gynecology Department. Participants were informed about the objective of the study and relevant issues before informed consent taken. Confidentiality was assured by using codes and their privacy was also kept.

\section{Results}

3.1. Sociodemographic Characteristics. Response rate for this study is $100 \%$. Out of 2348 laboring mothers who gave birth in the labor ward of JUMC during the 6 months of the study period 242(10.3\%) were by operative vaginal delivery(OVD). Out of all 92 (38\%) of them were in the age group of 20-24 years, the mean age of study participants was 24 .7years +/5years SD. Most 144(59.5\%) of them were from outside of Jimma Town. Almost all 237 (97.9\%) of them were married, and majority of them were Muslim by religion, Oromo by ethnicity, and housewives by occupational status, 161(66.5\%), $201(83.1 \%)$, and $101(41.7 \%)$ respectively. Those mothers who cannot read and write and with educational level of grade 1-8 each account for one-third of cases and 128(52.9\%) of mothers' monthly income is $500-1742 E T B$. (See Table 1 )

3.2. Obstetric Related Variables. According to this study $168(69.4 \%)$ of mothers were primiparas and $233(96.3 \%)$ of mothers who gave birth by OVD had at least one ANC visit and $118(48.8 \%)$ had four or more ANC visits. The commonest indication for OVD is found to be NRFHRP 136(56.2\%) which is followed by prolonged SSOL $58(24.0 \%)$. Of the types of OVDs forceps is more commonly used 192(79.3\%) and 
TABLE 1: Frequency distribution of sociodemographic characteristics of mothers who gave birth by OVD in JUMC December 1, 2016-May 30, 2017.

\begin{tabular}{|c|c|c|c|}
\hline Variable & Variable category & Frequency & Percent \\
\hline \multirow{5}{*}{ Age } & $15-19$ & 27 & 11.2 \\
\hline & $20-24$ & 92 & 38.0 \\
\hline & $25-29$ & 79 & 32.6 \\
\hline & $30-34$ & 31 & 12.8 \\
\hline & $35-39$ & 13 & 5.4 \\
\hline \multirow{2}{*}{ Place of residency } & Jimma Town & 98 & 40.5 \\
\hline & Outside Jimma town & 144 & 59.5 \\
\hline \multirow{6}{*}{ Ethnicity } & Oromo & 201 & 83.1 \\
\hline & Amhara & 13 & 5.4 \\
\hline & Tgrie & 3 & 1.2 \\
\hline & Gurage & 7 & 2.9 \\
\hline & Dawuro & 12 & 5.0 \\
\hline & Other & 6 & 2.5 \\
\hline \multirow{4}{*}{ Religion } & Muslim & 161 & 66.5 \\
\hline & Orthodox & 55 & 22.7 \\
\hline & Protestant & 24 & 9.9 \\
\hline & Other & 2 & .8 \\
\hline \multirow{5}{*}{ Occupation } & Housewife & 101 & 41.7 \\
\hline & civil servant & 39 & 16.1 \\
\hline & Farmer & 82 & 33.9 \\
\hline & Merchant & 11 & 4.5 \\
\hline & Other & 9 & 3.7 \\
\hline \multirow{6}{*}{ Educational status } & Illiterate & 77 & 31.8 \\
\hline & read and write only & 4 & 1.7 \\
\hline & grade $1-8$ & 81 & 33.5 \\
\hline & grade $9-10$ & 25 & 10.3 \\
\hline & grade11-12 & 31 & 12.8 \\
\hline & $>12$ & 24 & 9.9 \\
\hline \multirow{3}{*}{ Income of the family per month } & 500 ETB and below & 10 & 4.1 \\
\hline & 501-1742 ЕТВ & 128 & 52.9 \\
\hline & above 1742 & 104 & 43.0 \\
\hline \multirow{4}{*}{ Marital status } & Married & 237 & 97.9 \\
\hline & Single & 3 & 1.2 \\
\hline & Divorced & 1 & .4 \\
\hline & Widowed & 1 & .4 \\
\hline
\end{tabular}

vacuum deliveries were $50(20.7 \%)$ with ratio of $4: 1$. Most $132(54.5 \%)$ of the applied classification of OVD is low forceps or low vacuum and $110(45.5 \%)$ were outlet forceps or outlet vacuum. Out of 173(71.5\%) OVDs applied for those mothers who were being followed at labor ward of JUMC, 70 (28.9\%) of the laboring mothers had different grades of MSAF. The GA at delivery was between 37 and 42 weeks in 213 (88.0\%) of the laboring mothers. Fifteen mothers $(6.2 \%)$ had postterm pregnancy and $14(5.8 \%)$ were preterm deliveries. Majority $221(91.3 \%)$ of the newborns weigh 2500-3999 grams. (See Table 2 and Figure 1)

3.3. Neonatal Outcome and Maternal Sociodemographics. Of all mothers who gave birth by OVD during the study period $210(86.8 \%)$ had favorable neonatal outcome. Mothers in the group of 25-29 years and those from Jimma Town had the higher proportion of favorable neonatal outcome which is $71(89.9 \%)$ and $90(91.8 \%)$, respectively. Neonates of mothers who are farmers in occupation had the lowest proportion $64(78 \%)$ of favorable outcome and the proportion of those neonates from mothers who at least can read and write that had favorable outcome is higher $149(90.3 \%)$ when compared with proportion among illiterates 61(79.2\%). Mothers whose monthly income is greater than 1743ETB had higher $98(94.2 \%)$ proportion of favorable neonatal outcome and $205(86.5 \%)$ of those mothers who are married had neonates with favorable outcome. (see Table 3)

3.4. Neonatal Outcome and Obstetric Related Variables. The proportion of neonates who had favorable outcome among 
TABLE 2: Frequency distribution of obstetric related variables among mothers who gave birth by OVD in JUMC December 1, 2016-May 30, 2017.

\begin{tabular}{|c|c|c|c|}
\hline Obstetric related & Variable category & Frequency & Percent \\
\hline \multirow{3}{*}{ Parity } & $\mathrm{I}$ & 168 & 69.4 \\
\hline & II-IV & 53 & 21.9 \\
\hline & $\geq \mathrm{V}$ & 21 & 8.7 \\
\hline \multirow{3}{*}{ GA } & pre-term & 14 & 5.8 \\
\hline & Term & 213 & 88.0 \\
\hline & post term & 15 & 6.2 \\
\hline \multirow{2}{*}{ ANC follow up } & yes & 233 & 96.3 \\
\hline & no & 9 & 3.7 \\
\hline \multirow{4}{*}{ Number of ANC follow up } & one visit & 4 & 1.7 \\
\hline & two to three visit & 111 & 45.9 \\
\hline & four and above visit & 118 & 48.8 \\
\hline & No visit & 9 & 3.7 \\
\hline \multirow{2}{*}{ Type of OVD used } & vacuum & 50 & 20.7 \\
\hline & forceps & 192 & 79.3 \\
\hline \multirow{2}{*}{ Type of OVD applied } & low & 132 & 54.5 \\
\hline & outlet & 110 & 45.5 \\
\hline \multirow{2}{*}{ Time of application } & on arrival & 69 & 28.5 \\
\hline & followed & 173 & 71.5 \\
\hline \multirow{4}{*}{ Status of liquor } & clear & 172 & 71.1 \\
\hline & G1MSAF & 19 & 7.9 \\
\hline & G2MSAF & 17 & 7.0 \\
\hline & G3MSAF & 34 & 14.0 \\
\hline \multirow{3}{*}{ Weight of the newborn in grams } & $1500-2499$ & 14 & 5.8 \\
\hline & 2500-3999 & 221 & 91.3 \\
\hline & $>/=4000$ & 7 & 2.9 \\
\hline
\end{tabular}

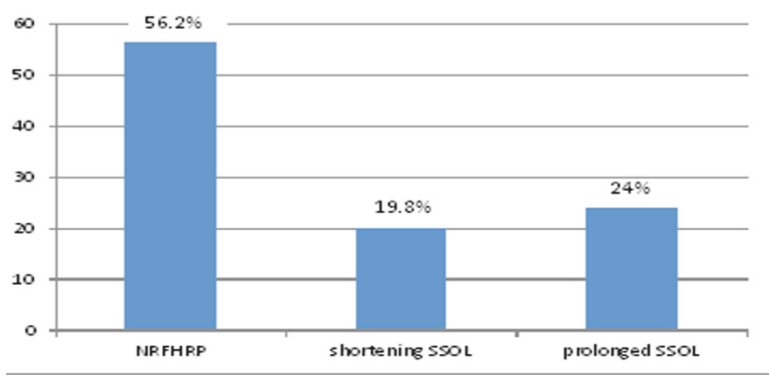

FIgURE 1: Proportion of indications for OVD among mothers who gave birth by OVD in JUMC December 1, 2016, to May 30, 2017.

para II-IV mothers and neonates born at term is higher which is $96.2 \%$ and $87.3 \%$ respectively. Those mothers who had at least one ANC visit have higher proportion of favorable neonatal outcome ( $88.0 \%$ versus $55.6 \%)$ and those who had four and above visits have better proportion 91.5\% with favorable outcome. Based on indication NRFHRP has the lower proportion of favorable outcome. Forceps deliveries are having higher proportion of favorable outcome $(91.7 \%$ versus $68 \%$ ) and the same holds for outlet (90.9\%). The higher proportion of mothers who were followed at the labor ward of
JUMC had favorable neonatal outcome than those for whom OVD is applied on arrival (91.7\% versus $75.4 \%)$. Half of those with G3MSAF have favorable outcome (see Table 4).

Of the 242 OVDs, neonates with low APGAR score (46 ) at first and fifth minutes were 95(39.3\%) and 16(6.6\%), respectively, and those with very low APGAR score (0-3) at first and fifth minutes were $10(4.1 \%)$ and $2(0.8 \%)$, respectively, and $47(19.4 \%)$ needed resuscitation. There were a total of $34(14.0 \%)$ admissions to NICU and 3 neonatal deaths before referral to NICU. Majority of the admissions were for MAS 15(44.1\%) followed by MAS+ subgaleal hemorrhage 10(29.4\%). There were different birth injuries like SGH, skull fracture, and bruising with a total of 15(44.1\%) injuries (one neonate with SGH requiring blood transfusion). The proportion of neonates with birth injury is higher among vacuum group than forceps deliveries (20\% versus $2.6 \%)$. Of the admitted cases to NICU 26(76.5\%) were improved, 6(17.6\%) died, and status of two of the cases is unknown. The commonly ascribed causes of neonatal deaths were respiratory failure, PNA, and multiorgan failure. (See Table 4)

3.5. Maternal Outcome and Sociodemographic Variables. Out of 242 mothers, 232(95.9\%) have favorable maternal outcome. Mothers in the group of 20-24 years had the higher proportion of favorable maternal outcome which is $97.8 \%$ and all 
TABLE 3: Distribution of neonatal outcome among different maternal sociodemographic characteristic categories who gave birth by OVD in JUMC December 1, 2016-May 30, 2017.

\begin{tabular}{|c|c|c|c|c|}
\hline \multirow{2}{*}{ Variable } & \multirow{2}{*}{ Variable category } & \multicolumn{2}{|c|}{ Neonatal outcome } & \multirow{2}{*}{ Total } \\
\hline & & Favorable outcome N (\%) & Unfavorable outcome $\mathbf{N}(\%)$ & \\
\hline \multirow{5}{*}{ Age } & $15-19$ & $24(88.9)$ & $3(11.1)$ & $27(100.0)$ \\
\hline & $20-24$ & $81(88.0)$ & $11(12.0)$ & $92(100.0)$ \\
\hline & $25-29$ & $71(89.9)$ & $8(10.1)$ & $79(100.0)$ \\
\hline & $30-34$ & $25(80.6)$ & $6(19.4)$ & $31(100.0)$ \\
\hline & $35-39$ & $9(69.2)$ & $4(30.8)$ & $13(100.0)$ \\
\hline \multirow{2}{*}{ Place of the residency } & Jimma Town & $90(91.8)$ & $8(8.2)$ & $98(100.0)$ \\
\hline & Outside Jimma town & $120(83.3)$ & $24(16.7)$ & $144(100.0)$ \\
\hline \multirow{5}{*}{ Occupation } & Housewife & $95(94.1)$ & $6(5.9)$ & $101(100.0)$ \\
\hline & civil servant & $33(84.6)$ & $6(15.4)$ & $39(100.0)$ \\
\hline & Farmer & $64(78.0)$ & $18(22.0)$ & $82(100.0)$ \\
\hline & Merchant & $9(81.8)$ & $2(18.2)$ & $11(100.0)$ \\
\hline & Other & $9(100.0)$ & $0(0.0)$ & $9(100.0)$ \\
\hline \multirow{6}{*}{ Educational status } & Illiterate & $61(79.2)$ & $16(20.8)$ & $77(100.0)$ \\
\hline & read and write only & $4(100.0)$ & $0(0.0)$ & $4(100.0)$ \\
\hline & grade $1-8$ & $75(92.6)$ & $6(7.4)$ & $81(100.0)$ \\
\hline & grade $9-10$ & $21(84.0)$ & $4(16.0)$ & $25(100.0)$ \\
\hline & grade11-12 & $27(87.1)$ & $4(12.9)$ & $31(100.0)$ \\
\hline & $>12$ & $22(91.7)$ & $2(8.3)$ & $24(100.0)$ \\
\hline \multirow{3}{*}{ Income of the family per month } & 500 ETB and below & $9(90.0)$ & $1(10.0)$ & $10(100.0)$ \\
\hline & 501-1742 ЕТВ & $103(80.5)$ & $25(19.5)$ & $128(100.0)$ \\
\hline & above 1742ETB & $98(94.2)$ & $6(5.8)$ & $104(100.0)$ \\
\hline \multirow{2}{*}{ Marital status } & Married & $205(86.5)$ & $32(13.5)$ & $237(100.0)$ \\
\hline & Others & $5(100.0)$ & $0(0.0)$ & $5(100.0)$ \\
\hline
\end{tabular}

mothers from Jimma Town have favorable maternal outcome. Those mothers who earn $>1742$ ETB per month have higher proportion 102(98.1\%) of favorable maternal outcome. (See Table 5)

3.6. Maternal Outcome and Obstetric Related Variables. The proportion of mothers who had favorable outcome among para II-IV mothers and for whom prolonged SSOL is an indication for OVD is higher which is $98.1 \%$ and $98.3 \%$, respectively. Based on type of OVD used the proportion of mothers with favorable maternal outcome is almost equal between forceps and vacuum deliveries (95.8\% versus $96.0 \%$ ). Almost all (99.1\%) of outlet forceps/vacuum deliveries have favorable maternal outcome. Of all 242 OVDs 8 cases $(3.3 \%)$ were complicated with $\mathrm{PPH}$ and the PPHs were secondary to three uterine atony and five episiotomy extension cases. Two of the eight PPH cases underwent per partum hysterectomy and three of them were transfused. There is one case complicated with fourth degree genital tear with no $\mathrm{PPH}$ and one maternal death after forceps is applied for shortening of SSOL for cardiac illness and the death is ascribed to be secondary to cardiac arrest. (See Table 6)

3.7. Factors Affecting Neonatal Outcome. Place of residence, occupation, income, parity, indication for OVD, type of instrument used for OVD, station at which OVD is applied, time of application, and status of liquor were variables identified as a candidate variable from bivariate logistic regression analysis and then fitted into the final multivariable logistic regression model using enter method to identify independent factors affecting the fetal outcome. This study shows that there is significant association between type of instrument used for OVD and neonatal outcome, $80 \%$ of mothers who gave birth by vacuum are less likely to have favorable neonatal outcome than those with forceps deliveries $(\mathrm{AOR}=0.228$, 95\%CI: 0.078, 0.671). Meconium stained amniotic fluid had shown association with neonatal outcome, $84 \%$ of mothers with G2MSAF (AOR=0.163, 95\%CI: 0.031, 0.858) and $90 \%$ of mothers with grade 3 MSAF (AOR $=0.088,95 \% \mathrm{CI}$ : $0.024,0.327$ ) are less likely to have favorable neonatal outcome than those with clear amniotic fluid. (see Table 7)

3.8. Factors Affecting Maternal Outcome. Income, indication for OVD, station at OVD application, and weight of newborn at delivery were variables identified as candidate variable from bivariate logistic regression analysis and then fitted into the final multivariable logistic regression model using enter method to identify independent factors affecting the maternal outcome. Neonatal birth weight had shown strong association with maternal outcome, almost all mothers with neonatal birth weight $>4000$ grams $(99.6 \%)$ are less likely to have favorable maternal outcome than those with neonatal 
TABLE 4: Distribution of neonatal outcome among mothers who gave birth by OVD in JUMC December 1, $2016-$ May 30, 2017.

\begin{tabular}{|c|c|c|c|c|}
\hline \multirow{2}{*}{ variable } & \multirow{2}{*}{ Variable category } & \multicolumn{2}{|c|}{ Neonatal outcome } & \multirow{2}{*}{ Total } \\
\hline & & Favorable outcome N (\%) & Unfavorable outcome N (\%) & \\
\hline \multirow{3}{*}{ Parity } & $\mathrm{I}$ & $146(86.9)$ & $22(13.1)$ & $168(100.0)$ \\
\hline & II-IV & $51(96.2)$ & $2(3.8)$ & $53(100.0)$ \\
\hline & $\geq \mathrm{V}$ & $13(61.9)$ & $8(38.1)$ & $21(100.0)$ \\
\hline \multirow{3}{*}{ GA in weeks } & pre-term & $12(85.7)$ & $2(14.3)$ & $14(100.0)$ \\
\hline & Term & $186(87.3)$ & $27(12.7)$ & $213(100.0)$ \\
\hline & post term & $12(80.0)$ & $3(20)$ & $15(100.0)$ \\
\hline \multirow{2}{*}{ ANC follow up } & yes & $205(88.0)$ & $28(12.0)$ & $233(100.0)$ \\
\hline & No & $5(55.6)$ & $4(44.4)$ & $9(100.0)$ \\
\hline \multirow{4}{*}{ Number of ANC follow up } & one visit & $3(75.0)$ & $1(25.0)$ & $4(100.0)$ \\
\hline & two to three visit & $94(84.7)$ & $17(15.3)$ & $111(100.0)$ \\
\hline & four and above visit & $108(91.5)$ & $10(8.5)$ & $118(100.0)$ \\
\hline & no visit & $5(55.6)$ & $4(44.4)$ & $8(100.0)$ \\
\hline \multirow{3}{*}{ Indication for OVD } & NRFHRP & $115(84.6)$ & $21(15.4)$ & $136(100.0)$ \\
\hline & shortening SSOL & $44(91.7)$ & $4(8.3)$ & $48(100.0)$ \\
\hline & prolonged SSOL & $51(87.9)$ & $7(12.1)$ & $58(100.0)$ \\
\hline \multirow{2}{*}{ Type of OVD used } & vacuum & $34(68.0)$ & $16(32.0)$ & $50(100.0)$ \\
\hline & forceps & 176(91.7) & $16(8.3)$ & 192(100.0) \\
\hline \multirow{2}{*}{ Type of OVD applied } & Low & $110(83.3)$ & $22(16.7)$ & $132(100.0)$ \\
\hline & outlet & $100(90.9)$ & $10(9.1)$ & $110(100.0)$ \\
\hline \multirow{2}{*}{ Time of application } & on arrival & $52(75.4)$ & $17(24.6)$ & $69(100.0)$ \\
\hline & followed & $158(91.7)$ & $15(8.3)$ & $173(100.0)$ \\
\hline \multirow{4}{*}{ Status of liquor } & clear & $163(94.8)$ & $9(5.2)$ & $172(100.0)$ \\
\hline & G1MSAF & $17(89.5)$ & $2(10.5)$ & $19(100.0)$ \\
\hline & G2MSAF & $13(76.5)$ & $4(23.5)$ & $17(100.0)$ \\
\hline & G3MSAF & $17(50.0)$ & $17(50.0)$ & $34(100.0)$ \\
\hline \multirow{3}{*}{ weight of the newborn in grams } & $1500-2499$ & $13(92.9)$ & $1(7.1)$ & $14(100.0)$ \\
\hline & $2500-3999$ & $192(86.9)$ & $29(13.1)$ & $221(100.0)$ \\
\hline & $>/=4000$ & $5(71.4)$ & $2(28.6)$ & $7(100.0)$ \\
\hline
\end{tabular}

birth weight of 2500-3999grams (AOR=0.007, 95\%CI: 0.000, 0.151 ), respectively. (see Table 8 )

\section{Discussion}

Prevalence of OVD application is $10.3 \%$ in JUMC and the finding is consistent with other studies. Although operative vaginal delivery may be performed, as infrequently as in $1.5 \%$ of deliveries in some countries, it may be as high as $15 \%$ in other countries. For example, in the United Kingdom, the rates of instrumental vaginal delivery range between $10 \%$ and $15 \%$; these rates have remained fairly constant. Of the total 242 OVDs, forceps and vacuum deliveries account for $8.2 \%$ and $2.1 \%$ of all the deliveries during the study period respectively with ratio of 4:1, but according to study done at Tikur Anbessa Hospital the ratio is 2:1 and it is not in line with the currently increasing proportion of vacuum deliveries which is 1:4. The higher difference in the proportion of forceps to vacuum deliveries from other studies can be due to the commonest indication being NRFHRP which needs faster delivery and the inconsistent supply of functioning vacuum extraction devices in the study area $[1,2,5,11]$.
Fetal distress (NRFHRP) was the commonest indication (56.2\%) for OVD among the 242 cases followed by prolonged SSOL $(24.0 \%)$ and those used to cut short SSOL (19.4\%) and the finding is consistent with other studies. For example, a five-year retrospective study done on trends of instrumental deliveries at a tertiary care teaching hospital in Puducherry, India, shows among the study participants the indications were nonreassuring fetal heart (45.3\%), prolonged second stage of labor (33.9\%), and maternal indication to shorten second stage of labor (13.1\%). The study done at the Tikur Anbessa Hospital also shows that the most common indication for OVD is fetal distress $(45.3 \%)[2,8]$.

According to our study the overall rate of complication is $17.3 \%$ (maternal $=4.1 \%$ and neonatal $=13.2 \%$ ). The commonest maternal complication was postpartum hemorrhage $(3.3 \%)$ and this can be explained by genital tract laceration which account for $62.5 \%$ of the $\mathrm{PPH}$ and prolonged labor also contributes PPH secondary to uterine atony. But the finding of rate of $\mathrm{PPH}$ among operative vaginal deliveries is much lower than study done at Aminu Kano Teaching Hospital, Kano, Nigeria, which is $9.5 \%$ and this may be due to lack of practice in documenting estimated blood loss and 
TABLE 5: Distribution of maternal outcome cross tabulated with sociodemographic characteristics among mothers who gave birth by OVD in JUMC December 1, 2016-May 30, 2017.

\begin{tabular}{|c|c|c|c|c|}
\hline \multirow{2}{*}{ Variables with category } & & \multicolumn{2}{|c|}{ Maternal outcome } & \multirow{2}{*}{ Total } \\
\hline & & Favorable outcome N (\%) & Unfavorable outcome N (\%) & \\
\hline \multirow{5}{*}{ Age } & $15-19$ & $26(96.3)$ & $1(3.7)$ & $27(100.0)$ \\
\hline & $20-24$ & $90(97.8)$ & $2(2.2)$ & $92(100.0)$ \\
\hline & $25-29$ & $74(93.7)$ & $5(6.3)$ & $79(100.0)$ \\
\hline & $30-34$ & $30(96.8)$ & $1(3.2)$ & $31(100.0)$ \\
\hline & $35-39$ & $12(92.3)$ & $1(7.7)$ & $13(100.0)$ \\
\hline \multirow{2}{*}{ Place of the residency } & Jimma Town & $98(100.0)$ & $0(0.0)$ & $98(100.0)$ \\
\hline & Outside Jimma town & $134(93.1)$ & $10(6.9)$ & $144(100.0)$ \\
\hline \multirow{5}{*}{ Occupation } & Housewife & $97(96.0)$ & $4(4.0)$ & $101(100.0)$ \\
\hline & civil servant & $39(100.0)$ & $0(0.0)$ & $39(100.0)$ \\
\hline & Farmer & $76(92.7)$ & $6(7.3)$ & $82(100.0)$ \\
\hline & Merchant & $11(100.0)$ & $0(0.0)$ & $11(100.0)$ \\
\hline & Other & $9(100.0)$ & $0(0.0)$ & $9(100.0)$ \\
\hline \multirow{6}{*}{ Educational status } & Illiterate & $71(92.2)$ & $6(7.8)$ & $77(100.0)$ \\
\hline & read and write only & $4(100.0)$ & $0(0.0)$ & $4(100.0)$ \\
\hline & grade $1-8$ & $78(96.3)$ & $3(3.7)$ & $81(100.0)$ \\
\hline & grade $9-10$ & $24(96.0)$ & $1(4.0)$ & $25(100.0)$ \\
\hline & gradel1-12 & $31(100.0)$ & $0(0.0)$ & $31(100.0)$ \\
\hline & $>12$ & $24(100.0)$ & $0(0.0)$ & $24(100.0)$ \\
\hline \multirow{3}{*}{ Income of the family per month } & 500 ETB and below & $8(80.0)$ & $2(20.0)$ & $10(100.0)$ \\
\hline & 501-1742 ЕТВ & $122(95.3)$ & $6(4.7)$ & $128(100.0)$ \\
\hline & above 1742 & $102(98.1)$ & $2(1.9)$ & $104(100.0)$ \\
\hline \multirow{2}{*}{ Marital status } & Married & $227(95.8)$ & $10(4.2)$ & $237(100.0)$ \\
\hline & Others & $5(100.0)$ & $0(0.0)$ & $5(100.0)$ \\
\hline
\end{tabular}

TABLE 6: Distribution of maternal outcome cross tabulated with maternal obstetric related variables among mothers who gave birth by OVD in JUMC December 1, 2016-May 30, 2017.

\begin{tabular}{|c|c|c|c|c|}
\hline \multirow{2}{*}{ Obstetric related factors } & & \multicolumn{2}{|c|}{ Maternal outcome } & \multirow{2}{*}{ Total } \\
\hline & & Favorable outcome N (\%) & Unfavorable outcome N (\%) & \\
\hline \multirow{3}{*}{ Parity } & $\mathrm{I}$ & $160(95.2)$ & $8(4.8)$ & $168(100.0)$ \\
\hline & II-IV & $52(98.1)$ & $1(1.9)$ & $53(100.0)$ \\
\hline & $\geq \mathrm{V}$ & $20(95.2)$ & $1(4.8)$ & $21(100.0)$ \\
\hline \multirow{2}{*}{ ANC follow up } & Yes & $223(95.7)$ & $10(4.3)$ & $233(100.0)$ \\
\hline & No & $9(100.0)$ & $0(0.0)$ & $9(100.0)$ \\
\hline \multirow{3}{*}{ Indication for OVD } & NRFHRP & $132(97.1)$ & $4(2.9)$ & $136(100.0)$ \\
\hline & shortening SSOL & $43(89.6)$ & $5(10.4)$ & $48(100.0)$ \\
\hline & prolonged SSOL & $57(98.3)$ & $1(1.7)$ & $58(100.0)$ \\
\hline \multirow{2}{*}{ Type of OVD used } & Vacuum & $48(96.0)$ & $2(4.0)$ & $50(100.0)$ \\
\hline & Forceps & $184(95.8)$ & $8(4.2)$ & 192(100.0) \\
\hline \multirow{2}{*}{ Type of OVD applied } & Low & $123(93.2)$ & $9(6.8)$ & $132(100.0)$ \\
\hline & Outlet & 109(99.1) & $1(.9)$ & $110(100.0)$ \\
\hline \multirow{2}{*}{ Time of application } & on arrival & $67(97.1)$ & $2(2.9)$ & $69(100.0)$ \\
\hline & Followed & $165(95.4)$ & $8(4.6)$ & $173(100.0)$ \\
\hline \multirow{3}{*}{ weight of the newborn in grams } & $1500-2499$ & $12(85.7)$ & $2(14.3)$ & $14(100.0)$ \\
\hline & 2500-3999 & $213((96.4)$ & $8(3.6)$ & $221(100.0)$ \\
\hline & $>/=4000$ & $7(100.0)$ & $0(0.0)$ & $7(100.0)$ \\
\hline
\end{tabular}


TABLE 7: Factors affecting neonatal outcome using multivariate logistic regression among mothers who gave birth by OVD in JUMC December 1, 2016-May 30, 2017.

\begin{tabular}{|c|c|c|c|c|c|c|}
\hline \multirow{2}{*}{ Variables with category } & & \multicolumn{2}{|c|}{ Neonatal outcome } & \multirow{2}{*}{ Crude OR(95\% CI) } & \multirow{2}{*}{$\mathrm{AOR}(95 \% \mathrm{CI})$} & \multirow{2}{*}{$\mathrm{P}$ value } \\
\hline & & Fav & Unfav & & & \\
\hline \multirow{2}{*}{ Place of the residency } & Jimma Town & 90 & 8 & $2.250(.966,5.241)$ & $.653(.176,2.429)$ & 0.525 \\
\hline & Outside Jimma town & 120 & 24 & 1 & 1 & \\
\hline \multirow{5}{*}{ Occupation } & Housewife & 95 & 6 & 1 & 1 & \\
\hline & civil servant & 33 & 6 & $.347(.105,1.152)$ & $0.282(.062,1.278)$ & 0.101 \\
\hline & Farmer & 64 & 18 & $.225(.085, .596)$ & $0.299(.061,1.462)$ & 0.136 \\
\hline & Merchant & 9 & 2 & $.284(.050,1.620)$ & $0.221(.029,1.692)$ & 0.146 \\
\hline & Other & 9 & 0 & $1.020(.000,2.310)$ & $1.110(.000,3.23)$ & 0.999 \\
\hline \multirow{3}{*}{ Income of the family per month } & 500 ETB and below & 9 & 1 & $1.000(.118,8.487)$ & $4.650(.248,87.109$ & 0.304 \\
\hline & 501-1742 ЕТВ & 103 & 25 & 1 & 1 & \\
\hline & above 1742 & 98 & 6 & $.490(229,1.051)$ & $1.551(.325,7.397)$ & 0.582 \\
\hline \multirow{3}{*}{ Parity } & $\mathrm{I}$ & 146 & 22 & 1 & 1 & \\
\hline & II-IV & 51 & 2 & $3.842(.873,16.917)$ & $2.719(.525,14.070)$ & 0.233 \\
\hline & $\geq \mathrm{V}$ & 13 & 8 & $.245(.091, .658)$ & $0.294(.072,1.197)$ & 0.088 \\
\hline \multirow{3}{*}{ Indication for OVD } & NRFHRP & 115 & 21 & 1 & 1 & \\
\hline & shortening SSOL & 44 & 4 & $2.009(.653,6.183)$ & $0.698(.155,3.146)$ & 0.640 \\
\hline & prolonged SSOL & 51 & 7 & $1.330(.532,3.328)$ & $0.906(.198,4.143)$ & 0.899 \\
\hline \multirow{2}{*}{ Type of OVD used $*$} & Vacuum & 34 & 16 & $.193(.088, .423)$ & $0.228(0.078,0.671)$ & 0.007 \\
\hline & Forceps & 176 & 16 & 1 & 1 & \\
\hline \multirow{2}{*}{ Type of OVD applied } & Low & 110 & 22 & 1 & 1 & \\
\hline & Outlet & 100 & 10 & $2.000(.903,4.429)$ & $1.604(.577,4.458)$ & 0.365 \\
\hline \multirow{2}{*}{ Time of application } & on arrival & 52 & 17 & $.290(.136, .622)$ & $0.436(.118,1.615)$ & 0.214 \\
\hline & Followed & 158 & 15 & 1 & 1 & \\
\hline \multirow{4}{*}{ Status of liquor* } & Clear & 163 & 9 & 1 & 1 & \\
\hline & G1MSAF & 17 & 2 & $.469(.094,2.352)$ & $0.574(.081,4.088)$ & 0.579 \\
\hline & G2MSAF & 13 & 4 & $.179(.049, .663)$ & $0.163(.031, .858)$ & 0.032 \\
\hline & G3MSAF & 17 & 17 & $.055(.021, .143)$ & $0.088(.024, .327)$ & 0.000 \\
\hline
\end{tabular}

* shows significant predictor variable with $\mathrm{p}<0.05$.

TABLE 8: Factors affecting maternal outcome using multivariate logistic regression among mothers who gave birth by OVD in JUMC December 1, 2016-May 30, 2017.

\begin{tabular}{|c|c|c|c|c|c|c|}
\hline \multirow{2}{*}{ Variables with category } & & \multicolumn{2}{|c|}{ Maternal outcome } & \multirow{2}{*}{ Crude OR(95\% CI) } & \multirow{2}{*}{$\mathrm{AOR}(95 \% \mathrm{CI})$} & \multirow{2}{*}{$P$ value } \\
\hline & & $\mathrm{Fav}$ & Unfav & & & \\
\hline \multirow{3}{*}{ Income of the family per month } & $500 \mathrm{ETB}$ and below & 8 & 2 & $0.058(0.007,0.467)$ & $0.004(.000,0.133)$ & 0.057 \\
\hline & 501-1742 ЕТВ & 122 & 6 & 1 & 1 & \\
\hline & above 1742ETB & 102 & 2 & $0.208(0.041,1.053)$ & $0.060(0.004,0.961)$ & 0.073 \\
\hline \multirow{3}{*}{ Indication for OVD } & NRFHRP & 132 & 4 & 1 & 1 & \\
\hline & shortening SSOL & 43 & 5 & $0.261(0.067,1.014)$ & $0.166(0.026,1.067)$ & 0.058 \\
\hline & prolonged SSOL & 57 & 1 & $1.727(0.189,15.796)$ & $1.632(.146,18.298)$ & 0.691 \\
\hline \multirow{2}{*}{ Type of OVD applied } & Low & 123 & 9 & 1 & 1 & \\
\hline & Outlet & 109 & 1 & $7.976(0.994,63.969)$ & $8.262(0.670,101.942)$ & 0.100 \\
\hline \multirow{3}{*}{ weight of the newborn in grams* } & $1500-2499$ & 12 & 2 & $0.167(0.031,0.919)$ & $0.355(0.050,2.546)$ & 0.303 \\
\hline & 2500-3999 & 213 & 8 & 1 & 1 & \\
\hline & $>/=4000$ & 7 & 0 & $0.070(0.011,0.435)$ & $0.007(0.000,0.151)$ & 0.002 \\
\hline
\end{tabular}

* shows significant predictor variable with $\mathrm{p}<0.05$; Fav: favorable; Unfav: unfavorable. 
determining postoperative hematocrit after at least suspected $\mathrm{PPH}$ cases $[2,10]$.

Vacuum deliveries are associated with significant fetal morbidity and among vacuum deliveries fetal morbidity is $32 \%$ and $20 \%$ were complicated with subgaleal hemorrhage. The rates of severe birth asphyxia and ENND were $4.9 \%$ and $3.7 \%$, respectively. This is compared to the findings of various studies; for example, according to study carried out at the Aminu Kano Teaching Hospital, Kano, Nigeria, the rate of asphyxia and ENND is $4.8 \%$ and $3.8 \%$, respectively. But, this may not be truly attributable to the procedure as the asphyxia may be the outcome of the events of labor that indicated the intervention than the operative vaginal procedure itself $[3,10,12,13]$.

Among the 242 OVDs, neonates with low APGAR scores (4-6) at first and fifth minutes were 95(39.3\%) and 16(6.6\%), respectively, and those with very low APGAR score (0-3) at first and fifth minutes were $10(4.1 \%)$ and $2(0.8 \%)$, respectively. Compared to other studies the rate of low APGAR score $(<7)$ is higher and this can be explained by the fact that fetal distress was the commonest indication for OVD according to our study and also the commonest cause of low APGAR scores at the $1^{\text {st }}$ and fifth minute among indications of operative vaginal deliveries $[2,14-16]$. Our study and most other studies showed that there is significant association between type of instrument used for OVD and neonatal outcome, $80 \%$ of mothers who gave birth by vacuum are less likely to have favorable neonatal outcome than those with forceps deliveries. According to one of the studies, cephalhematoma, in particular, is more common after vacuum-assisted extraction than forceps delivery (approximately 15 versus 2 percent). The risks of fetal injury are generally instrument specific, with vacuum deliveries accounting for statistically significantly higher rates of cephalhematoma, and subgaleal and retinal hemorrhages, and forceps deliveries accounting for a no significantly higher rate of scalp/facial injuries [11, 1720].

Meconium stained amniotic fluid had shown association with neonatal outcome, $90 \%$ of mothers with grade $3 \mathrm{MSAF}$ are less likely to have favorable neonatal outcome than those with clear amniotic fluid. Studies showed that the association can be explained by passage of meconium secondary to already existing intrauterine fetal compromise or asphyxia $[11,21-23]$. Neonatal birth weight had shown strong association with maternal outcome, $99.6 \%$ of those mothers who gave birth to neonate with birth weight $>4000$ grams are less likely to have favorable maternal outcome when compared to those with normal birth weight. This finding as it is proven on different literatures, macrosomia attributes for PPH secondary to both uterine atony and perineal lacerations $[4,11$, 24].

\section{Conclusion and Recommendation}

5.1. Conclusion. The prevalence of OVD among the 2348 laboring mothers who gave birth at JUMC during the study period is $10.3 \%$. The commonest indication for OVD is NRFHRP (56.2\%) followed by prolonged SSOL (24.0\%) and shortening SSOL (19.8\%). Among mothers who gave birth by OVD, $86.8 \%$ had favorable neonatal outcome. Near to all (95.9\%) of mothers who gave birth by OVD had favorable maternal outcome. Type of instrument used for OVD and presence of MSAF are factors affecting neonatal outcome. Neonatal birth weight is significant factor affecting maternal outcome.

5.2. Recommendations. Nearby health facilities should be equipped with and use instruments needed for OVD as majority (59.5\%) of mothers were referred from other facilities, application of OVD does not need referral to tertiary hospital. Although the ANC coverage among mothers with OVD is higher (96.3\% had at least one ANC visit and $48.8 \%$ had four and above ANC visit) than the national and Oromia figure, mothers should be encouraged to have the recommended number of ANC follow-up and further study is needed to know and address the reason why mothers are not having the ANC visit as per the recommendation. The ratio of forceps to vacuum delivery according to this study is 4:1 but currently vacuum has worldwide acceptance because of technical simplicity to apply and relatively less maternal trauma, so using vacuum for OVD should be encouraged. Documenting estimated blood loss and determining postoperative hematocrit after at least suspected PPH cases should be practiced by health professionals attending OVDs, as none of patients' charts contain adequate data about the circumstance of delivery and that can be evidenced by relatively lower rate of PPH. The commonest maternal complication was postpartum hemorrhage (3.3\%). The PPH cases were higher among mothers who gave birth to neonates with birth weight $>4000$ grams and the study had shown the association. Thus, there is need to anticipate postpartum hemorrhage in operative vaginal deliveries special in case macrosomia suspected.

\section{Abbreviations}

ANC: Antenatal care

ARM: Artificial rupture of membrane

FHR: Fetal heart rate

IUFD: Intrauterine fetal death

ENND: Early neonatal death

EFW: Estimated fetal weight

GA: Gestational age

HCT: Hematocrit

HTN: Hypertension

JUMC: Jimma University Medical Center

MSAF: Meconium stained amniotic fluid

NICU: Neonatal intensive care unit

ObGy: Obstetrics and Gynecology

OL: Obstructed labor

OVD: Operative vaginal delivery

PE: Preeclampsia

PPH: Postpartum hemorrhage

PNA: Perinatal asphyxia

ROM: Rupture of membrane

SSOL: Second stage of labor

SVD: Spontaneous vaginal delivery 
SGH: Subgaleal hemorrhage

WHO: World Health Organization.

\section{Data Availability}

The data used to support the findings of this study are included within the article.

\section{Ethical Approval}

Ethical clearance and an approval letter were obtained from Jimma University, Institute of Health-Institutional Reviewing Board, then support letter was obtained from JUMC administrative office.

\section{Consent}

All parties involved (Jimma University, study subjects, and authors) agreed to publish on international peer reviewed journal which is Hindawi-Journal of Pregnancy. During data collection, all participants informed and agreed on the major objective of the study which is for academic purpose including publication. Study participants were informed about the objective and details of the study including publication. Informed verbal consent was obtained from each subject. Confidentiality was maintained by using anonymous codes and the patients' chart number.

\section{Conflicts of Interest}

All authors declare that they have no any financial and nonfinancial conflicts of interest. None of the authors of this paper has a financial or personal relationship with other people or organizations that could inappropriately influence or bias the content of the paper.

\section{Authors' Contributions}

Zenebe Hubena had made substantial contributions to conception and design, acquisition of data, and analysis and interpretation of data. Ahadu Workneh and Yibeltal Siraneh prepared the manuscript critically for important intellectual content and worked together with Zenebe Hubena starting from proposal development to report writing. All authors read and approved the final manuscript.

\section{Acknowledgments}

The authors would like to express their deepest gratitude and appreciation to mothers, health professionals, and secretary of ObGy Department. They also acknowledge Jimma University, Institute of Health-IRB, for securing ethical letter timely and for the fund provided.

\section{References}

[1] F. Williams, J. L. Gary Cunningham Kenneth, Y. Bloom Catherine et al., Operative Vaginal Delivery, 24th edition, 2014.
[2] Y. Berhan and A. Abdela, "Emergency obstetric performance with emphasis on operative delivery outcome: Does it reflect the quality of care?" Ethiopian Journal of Health Development, vol. 18, no. 2, 2005.

[3] Instrumental Vaginal Delivery, The Royal Australian and New Zealand College of Obstetricians and Gynecologists, 2012.

[4] Royal College of Obstetricians and Gynecologists (RCOG), Operative Vaginal Delivery Guideline Number 26-Jan 2011, Clinical Green Top Guidelines, RCOG Press, London, UK, 2011.

[5] S. G. Gabbe, R. Jennifer, J. Niebyl, and S. Leigh, Operative Vaginal Delivery: Normal and Problem Pregnancies, An Imprint of Elsevier Inc., Philadelphia, Pa, USA, 6th edition, 2012.

[6] S. E. Adaji, S. O. Shittu, and S. T. Sule, "Operative vaginal deliveries in Zaria, Nigeria," Annals of African Medicine, vol. 8, no. 2, pp. 95-99, 2009.

[7] H. Alan, d. Cherney, N. Lauren, G. Murphy, and L. Neri, Current Diagnosis and Treatment Obstetrics \& Gynecology, 11th edition, 2013.

[8] W. N. Kabiru, D. Jamieson, W. Graves, and M. Lindsay, "Trends of instrumental deliveries at a tertiary care teaching hospital," The American College of Obstetrics and Gynecology Press, vol. 5, no. 7, pp. 20-32, 2015.

[9] S. Abha and R. Pratibha, "A comparative study of feto-maternal outcome in instrumental vaginal delivery," The Journal of $\mathrm{Ob}$ stetrics and Gynecology of India, vol. 61, no. 6, pp. 663-666, 2011.

[10] I. A. Yakasai, I. S. Abubakar, and E. M. Yunus, "Vacuum Delivery in a Tertiary Institution, in Northern Nigeria: A 5-Year Review," Open Journal of Obstetrics and Gynecology, vol. 05, no. 04, pp. 213-218, 2015.

[11] Up to date version 21.2, operative vaginal delivery, March 2013.

[12] Ethiopian Demographics Health Survey (EDHS), Central Statistical Agency, 2016.

[13] R. R. Patel and D. J. Murphy, "Forceps delivery in modern obstetric practice," BMJ, vol. 328, no. 7451, pp. 1302-1305, 2004.

[14] SOGC clinical practice guidelines, guidelines for operative vaginal birth No. 148, August 2004.

[15] R. Johanson and V. Menon, "Vacuum extraction versus forceps for assisted vaginal delivery," The Cochrane Collaboration, 2007.

[16] Althabe F., Vacuum Extraction versus Forceps for Operative Vaginal Delivery: RHL Practical Aspects (last revised: 2002), The WHO Reproductive Health Library, Oxford, UK, 2004.

[17] R. A. Mesleh, H. M. Al-Sawadi, and A. M. Kurdi, "Comparison of maternal and infant outcomes between vacuum extraction and forceps deliveries," Saudi Medical Journal, vol. 23, no. 7, pp. 811-813, 2002.

[18] S. Meakin, "Procedures in obstetrics," in Mayes' midwifery, S. MacDonald, J. Magill-Cuerden, and S. obstetrics. MacDonald, Eds., pp. 839-850, Bailliere Tindall, London, UK, 14th edition, 2011.

[19] K. D. Gregory, S. Jackson, L. Korst, and M. Fridman, "Cesarean versus vaginal delivery: Whose risks? whose benefits?" American Journal of Perinatology, vol. 29, no. 1, pp. 7-18, 2012.

[20] American College of Obstetricians and Gynecologists, Operative Vaginal Delivery, ACOG Practice Bulletin 17, Washington, DC, Was, USA, 2014.

[21] R. B. Johanson and B. K. Menon, "Vacuum extraction versus forceps for assisted vaginal delivery," Cochrane Database of Systematic Review, vol. 2, 2004.

[22] K. Demissie, G. G. Rhoads, J. C. Smulian et al., "Operative vaginal delivery and neonatal and infant adverse outcomes: Population based retrospective analysis," British Medical Journal, vol. 329, no. 7456, pp. 24-26, 2004. 
[23] J. P. O’Grady, C. S. Pope, and D. E. Hoffman, "Forceps delivery," Best Practice \& Research Clinical Obstetrics \& Gynaecology, vol. 16, no. 1, pp. 1-16, 2002.

[24] N. Prapas, I. Kalogiannidis, S. Masoura et al., "Operative vaginal delivery in singleton term pregnancies: Short-term maternal and neonatal outcomes," Hippokratia, vol. 13, no. 1, pp. 41-45, 2009. 


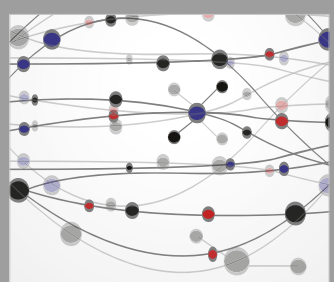

The Scientific World Journal
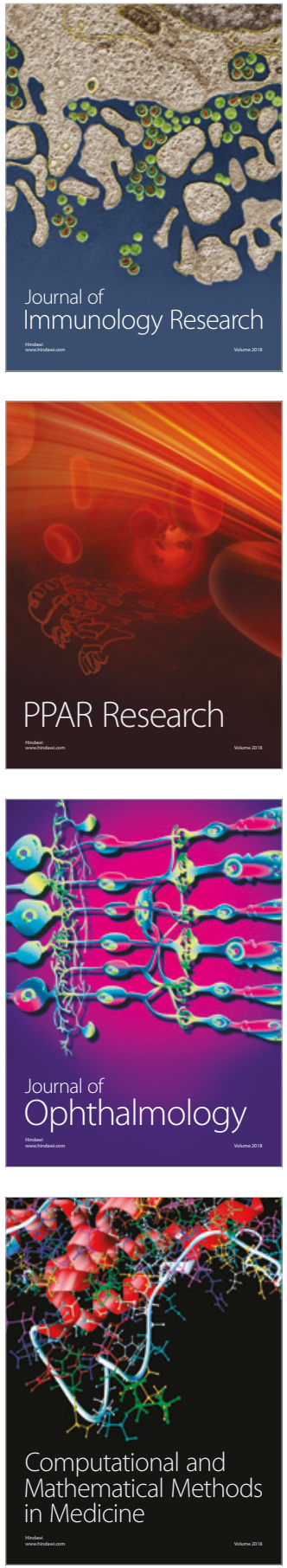

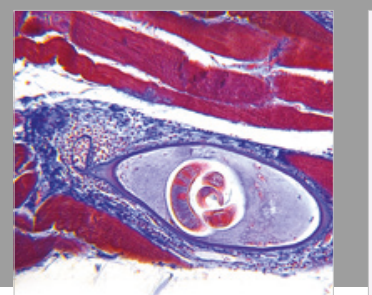

Gastroenterology Research and Practice

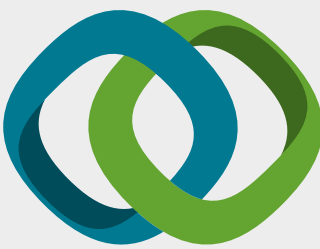

\section{Hindawi}

Submit your manuscripts at

www.hindawi.com
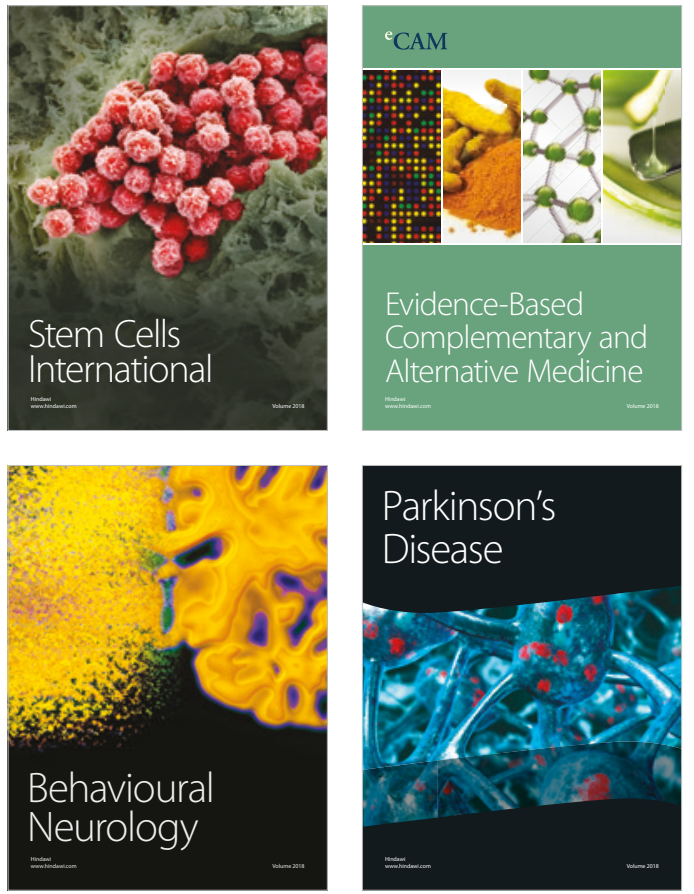

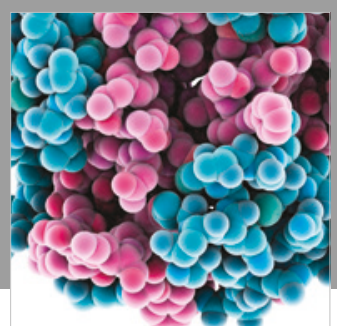

ournal of

Diabetes Research

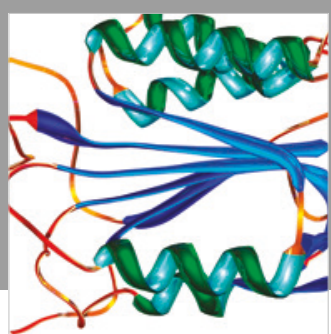

Disease Markers
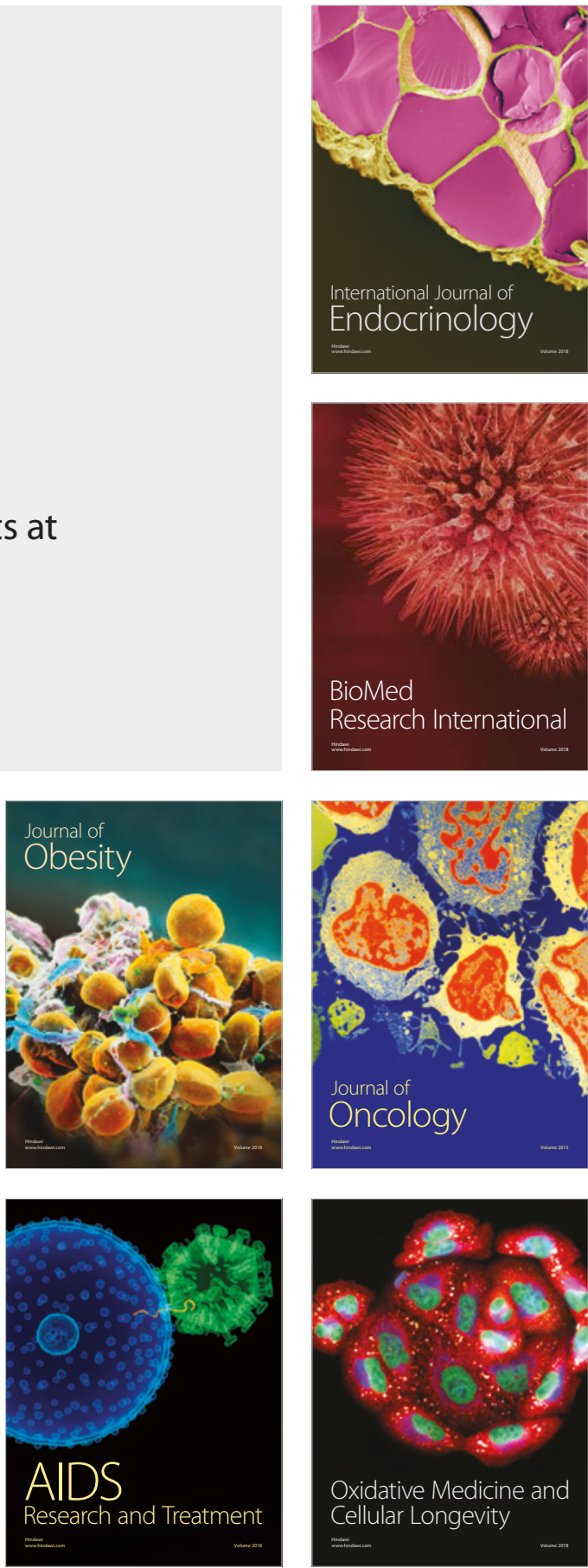